\title{
Fish oil supplemented for 9 months does not improve glycaemic control or insulin sensitivity in subjects with impaired glucose regulation: a parallel randomised controlled trial
}

\author{
Louise F. Clark ${ }^{1,2}$, M. C. Thivierge ${ }^{1}$, Claire A. Kidd ${ }^{1}$, Susan C. McGeoch ${ }^{2}$, Prakash Abraham², \\ Donald W. M. Pearson ${ }^{2}$, Graham W. Horgan ${ }^{3}$, Grietje Holtrop ${ }^{3}$, Frank Thies ${ }^{1}$ and Gerald E. Lobley ${ }^{1 *}$ \\ ${ }^{1}$ The Rowett Institute of Nutrition and Health, University of Aberdeen, Aberdeen AB21 9SB, UK \\ ${ }^{2}$ Aberdeen Diabetes Centre, Aberdeen Royal Infirmary, Aberdeen AB25 2ZP, UK \\ ${ }^{3}$ Biomathematics and Statistics Scotland, Aberdeen AB21 9SB, UK \\ (Submitted 14 May 2015 - Final revision received 1 October 2015 - Accepted 1 October 2015)
}

\section{Abstract}

The effects of fish oil (FO) supplementation on glycaemic control are unclear, and positive effects may occur only when the phospholipid content of tissue membranes exceeds $14 \%$ as $n-3$ PUFA. Subjects ( $n 36$, thirty-three completed) were paired based on metabolic parameters and allocated into a parallel double-blind randomised trial with one of each pair offered daily either $6 \mathrm{~g}$ of FO (3.9 g $n$-3 PUFA) or $6 \mathrm{~g}$ of maize oil (MO) for 9 months. Hyperinsulinaemic-euglycaemic-euaminoacidaemic (HIEGEAA) clamps (with $\left[6,6^{2} \mathrm{H}_{2}\right.$ glucose]) were performed at the start and end of the intervention. Endogenous glucose production (EGP) and whole-body protein turnover (WBPT) were each measured after an overnight fast. The primary outcome involved the effect of oil type on insulin sensitivity related to glycaemic control. The secondary outcome involved the effect of oil type on WBPT. Subjects on FO ( $n$ 16) had increased erythrocyte $n-3$ PUFA concentrations $>14 \%$, whereas subjects on MO $(n 17)$ had unaltered $n$-3 PUFA concentrations at $9 \%$. Type of oil had no effect on fasting EGP, insulin sensitivity or total glucose disposal during the HIEGEAA clamp. In contrast, under insulin-stimulated conditions, total protein disposal $(P=0 \cdot 007)$ and endogenous WBPT $(P=0.001)$ were both increased with FO. In an associated pilot study ( $n$ 4, three completed), although $n$-3 PUFA in erythrocyte membranes increased to $>14 \%$ with the FO supplement, the enrichment in muscle membranes remained lower $(8 \% ; P<0 \cdot 001)$. In conclusion, long-term supplementation with FO, at amounts near the safety limits set by regulatory authorities in Europe and the USA, did not alter glycaemic control but did have an impact on WBPT.

Key words: Fish oil: Glycaemic control: Insulin sensitivity: Protein metabolism: $\boldsymbol{n}$-3 PUFA membrane enrichment

In many Western societies, type 2 diabetes affects $5-8 \%$ of the population with an associated burden on health resources ${ }^{(1)}$. This incidence is associated, in part, with the increase in global obesity, as approximately $80 \%$ of people with type 2 diabetes are overweight or obese ${ }^{(1)}$. The transition to, and onset of, type 2 diabetes is characterised by insulin resistance ${ }^{(2)}$, and in both people who have developed diabetes and those in a "prediabetes' state altered lifestyle including exercise and/or weight loss can improve glycaemic control ${ }^{(3-5)}$. Nonetheless, continued compliance with such interventions is often unsatisfactory and other interventions have been sought.

One approach involves supplementation with long-chain $n-3$ PUFA, notably EPA and DHA, found in fish and other marine oils $^{(6,7)}$. Their potential benefit was noted several decades ago in Alaskan Inuit who had a low prevalence of type 2 diabetes even when obese ${ }^{(8,9)}$ - a feature lost when they adopted a non-traditional lifestyle ${ }^{(10)}$. The role of long-chain $n$-3 PUFA was supported by rodent studies where supplementation with $n-3$ PUFA ameliorated the insulin resistance caused by a diet rich in $\mathrm{SFA}^{(11)}$. Nonetheless, supplementation of human diets with $n$-3 PUFA has produced inconsistent outcomes, with a few studies reporting positive outcomes ${ }^{(4,12-15)}$, but with these counterbalanced by other publications that showed negative responses ${ }^{(16-20)}$. In practice, however, the majority of studies reported show either a null or mixed outcome ${ }^{(5,21-37)}$. On the basis of such variable outcomes, it is not surprising that a metaanalysis of the available literature data concluded that there was no benefit of fish oil (FO) supplementation, at least in terms of aspects of glycaemic control ${ }^{(38)}$.

The reason for these inconsistent outcomes of FO supplementation in humans may have a basis from more recent studies in farm species where responses in both glucose and

Abbreviations: BCAA, branched-chain amino acids; EGP, endogenous glucose production; FO, fish oil; HIEGEAA, hyperinsulinaemic-euglycaemiceuaminoacidaemic; MO, maize oil; MOP, 4-methyl-2-oxo pentanoic acid.

* Corresponding author: Dr G. E. Lobley, fax +44 1224438 699, email g.lobley@abdn.ac.uk 
protein metabolism were not observed until a threshold phospholipid enrichment in tissue membranes was achieved ${ }^{(39,40)}$. Such membrane phospholipid enrichments may not be attained in many of the human studies where either low doses of FO and (or) short intervention periods were employed, and therefore may not achieve values associated with positive health outcomes $^{(41)}$. Interestingly, recent studies in humans have reported that FO supplementation may impact on muscle protein synthesis over relatively short timescales $\left(8\right.$ weeks ${ }^{(37,42)}$ ), which might indicate differences in insulin sensitivity between glucose and protein metabolism.

Therefore, the present study was based on a dose of $n-3$ PUFA $(3.9 \mathrm{~g} / \mathrm{d})$ that is between the upper safe limit recommended in the USA $(3 \mathrm{~g} / \mathrm{d})^{(43)}$ and Europe $(5 \mathrm{~g} / \mathrm{d})^{(44)}$ and supplied over a 9-month period to older subjects with impaired glucose regulation. The primary outcome was to assess whether this supplementation improved insulin sensitivity in terms of glycaemic control. The secondary outcome was to examine whether the supplementation altered whole-body protein metabolism. A pilot study was also conducted to investigate whether n-3 PUFA enrichments in membranes of erythrocytes provided good surrogate markers of the phospholipid content in skeletal muscles.

\section{Methods}

\section{Subjects and study design}

Male and post-menopausal female Caucasian subjects were considered eligible for the study if aged between 40 and 61 years and had at least one of the following: impaired fasting glucose (fasting plasma glucose $6.1-6.9 \mathrm{mmol} / \mathrm{l}$ ); impaired glucose tolerance (plasma glucose $7 \cdot 8-11.1 \mathrm{mmol} / \mathrm{l}$ following a $2 \mathrm{~h} 75 \mathrm{~g}$ oral glucose tolerance test); type 2 diabetes mellitus newly diagnosed as a result of screening for this study but with $\mathrm{HbA} 1 \mathrm{c}<53 \mathrm{mmol} / \mathrm{mol}(7 \%)$ and fasting plasma glucose $>5.5 \mathrm{mmol} / \mathrm{l}$ but not requiring hypoglycaemic therapy. Exclusion criteria were diabetes requiring hypoglycaemic therapy, use of anticoagulants, alcoholism, hepatic or renal failure, anaemia, CVD or respiratory disease, malignancy, epilepsy, regular steroid or non-steroidal anti-inflammatory drug treatment plus any objections raised by the volunteer's general practitioner. Medication with stains was not an exclusion criterion. Recruitment was under the supervision of the first author (L. F. C.), a Specialist Registrar in diabetes care.

A total of 108 subjects were approached after the screening procedure. Of these, fifty-one did not respond, whereas another seventeen did not meet eligibility criteria. Those who were eligible ( $n$ 40) then elected to undergo at the start and end of the interventions either measures of insulin sensitivity ( $n$ 36), based on the hyperinsulinaemic-euglycaemic-euaminoacidaemic (HIEGEAA) clamp procedure, or instead provide muscle biopsies ( $n$ 4) for a pilot trial. This study was conducted according to the guidelines laid down in the Declaration of Helsinki. The trial was registered (NCT01241474; https://clinicaltrials.gov/) and ethics approval was obtained from the North of Scotland Research Ethics Committee. All the subjects gave their written informed consent. Three subjects withdrew from the clamp cohort for various reasons: development of type 2 diabetes mellitus requiring oral hypoglycaemic therapy (one volunteer), vasovagal event during the first HIEGEAA clamp (one volunteer) and general health deterioration (one volunteer). These occurred at or after the first clamp, and all the data obtained were excluded, with $n 17$ remaining in the MO cohort and $n 16$ in the FO cohort. One volunteer withdrew from the muscle biopsy cohort following discomfort from the first procedure.

\section{Design and treatments}

At enrolment, volunteers underwent a 2-month introductory period with the dietary $n-3: n-6$ ratio standardised to $1: 6$ by supply of oils for cooking and dressings (soya:sunflower oils used in a 3:1 ratio) and a spread (Flora Buttery ${ }^{\mathrm{TM}}$ ). Volunteers continued to use these oils and spread throughout the study. Height and weight were measured at enrolment as was RMR determined by indirect calorimetry as described previously ${ }^{(45)}$. Body composition was determined by air-displacement plethysmography (BOD POD ${ }^{\circledR}$, Body Composition System, Life Measurement Instrument) at the beginning and end of the study ${ }^{(45)}$. These procedures were carried out at the Human Nutrition Unit of the Rowett Institute of Nutrition and Health.

The daily $n$-3 PUFA supplement contained $6 \mathrm{~g}$ of FO (menhaden, Pacific herring) as $6 \times 1 \mathrm{~g}$ of EPAX $6000 \mathrm{TG}$ (EPAX AS). Although the nominal content of EPA + DPA in the oil was $50 \%$, the actual composition of the 6000T batch included EPA $39.8 \%$, DPA $3.6 \%$, DHA $25.5 \%$ and $\alpha$-linolenic acid $2.8 \%$ when assessed by GC. The actual daily intake of EPA plus DHA $(3.9 \mathrm{~g} / \mathrm{d})$ was therefore above the safe limit $(3 \mathrm{~g} / \mathrm{d})$ recommended by the US Food and Drug Administration ${ }^{(43)}$ but within the $5 \mathrm{~g} / \mathrm{d}$ set by the European Food Safety Authority ${ }^{(44)}$. The control supplement consisted of maize oil (MO, $6 \times 1 \mathrm{~g}$ capsules daily) also supplied by EPAX and contained $<2 \%$ EPA plus DHA.

In order to match the treatment groups for the clamp cohort, the initial volunteers after their first HIEGEAA clamp were randomly assigned to either FO or MO treatments via a doubleblind procedure, using a computer-generated randomisation list and supervised by an independent statistician. If a subsequent volunteer of the same sex required an infusion rate of glucose ( $\mathrm{mg} / \mathrm{min}$ per $\mathrm{kg}$ fat-free mass (FFM)) during the 3rd hour of the clamp within $25 \%$ of that of an unpaired earlier volunteer, they were paired together and given the alternative oil as the treatment. For the last three volunteers, this closeness of fit based on glucose infusion rate was not achieved (difference $>25 \%$ ), and thus alternative criteria of amino acid disposal and body composition were used to complete one pairing while the other remained unpaired. Capsules of the two oils were identical in outward appearance and were provided via the double-blind procedure in similar containers labelled sequentially under the supervision of an independent nutritionist. Neither volunteers nor researchers knew which treatment was allocated.

Each month, subjects attended the Rowett Institute of Nutrition and Health for review. They completed a brief health questionnaire, received new oil capsules, were weighed and overnight fasted blood samples were collected and 
subsequently separated into erythrocytes and plasma, with portions of each stored at $-8^{\circ} \mathrm{C}$ for further analyses.

\section{Hyperinsulinaemic-euglycaemic-euaminoacidaemic clamp and biopsy procedures}

The thirty-three volunteers (twenty men and thirteen women aged 51-69 years) underwent two HIEGEAA clamps in the Department of Diabetes, Aberdeen Royal Infirmary, Aberdeen, UK. The first was after the 2-month introductory period and the second after 9 months of oil supplementation. Dietary recommendations were given for the $3 \mathrm{~d}$ before the clamps, standardised for both quantity $(1.5 \times \mathrm{RMR})$ and macronutrient composition (52\% carbohydrate, $15 \%$ protein and $33 \%$ fat).

After an overnight fast (from 19.00 hours the day before), subjects were cannulated in a dorsal hand or wrist vein (retrograde, for sampling) and in an antecubital vein (antegrade, for infusions using a three-way tap) of the contralateral arm. The blood samples were 'arterialised' by placing the hand in a warm blanket (Dreamland Thermo Therapy Heatpad). Before infusions, four background samples were obtained at 5-min intervals to determine baseline glycaemia. Volunteers then received a prime dose of $7.8 \mathrm{mg} / \mathrm{kg}$ FFM D- $\left[6,6-{ }^{2} \mathrm{H}_{2}\right]$ glucose and $0.076 \mathrm{mg} / \mathrm{kg}$ FFM per min L- $\left[1-{ }^{13} \mathrm{C}\right]$ leucine followed by a $2-\mathrm{h}$ infusion of $0.075 \mathrm{mg} / \mathrm{kg}$ FFM per min $\mathrm{D}-\left[6,6-{ }^{2} \mathrm{H}_{2}\right]$ glucose and $0.0126 \mathrm{mg} / \mathrm{kg}$ FFM per min $\mathrm{L}-\left[1-{ }^{13} \mathrm{C}\right]$ leucine. During the last $30 \mathrm{~min}$ of infusion, six plasma samples were obtained at 5-min intervals and concentrations of glucose (glucose oxidase method; Yellow Springs Instrument) and plasma branched-chain amino acids (BCAA) ${ }^{(46)}$ were determined. Portions of plasma were also stored at $-80^{\circ} \mathrm{C}$ for subsequent analyses of glucose and leucine oxo-acid enrichments.

Immediately after this 2 -h infusion, the 3 -h hyperinsulinaemic clamp was initiated. First, 21 units of insulin (Human Actrapid; Novo Nordisk) was mixed in $56 \mathrm{ml} 0.9 \%$ saline and $4 \mathrm{ml}$ of the subject's plasma in a syringe and delivered through a syringe pump (Graseby Medical Ltd). The infusion rate was based on body surface area and set at $160 \mathrm{mU} / \mathrm{m}^{2}$ per min for $4 \mathrm{~min}$, then $80 \mathrm{mU} / \mathrm{m}^{2}$ per min for $4 \mathrm{~min}$ and finally maintained at a rate of $40 \mathrm{mU} / \mathrm{m}^{2}$ per $\mathrm{min}$ for the next $172 \mathrm{~min}$. Euglycaemia $( \pm 5 \%$ of fasting glucose concentration or at $5.5 \mathrm{~mm}$ if fasting concentration was $>5.5 \mathrm{~mm}$ ) and euaminoacidaemia ( $\pm 10 \%$ fasting BCAA concentration) were maintained during the clamp procedure by separate variable rate infusions of $20 \%$ dextrose (Fresenius Kabi) enriched to 3 mole percent excess (MPE) with D-[6,6- $\left.{ }^{2} \mathrm{H}_{2}\right]$ glucose (Cambridge Isotope Laboratories Inc.) and vamin 14 (Fresenius Kabi) enriched to $5 \mathrm{MPE}$ with $\mathrm{L}-\left[1-{ }^{13} \mathrm{C}\right]$ leucine (Cambridge Isotope Laboratories Inc.). Vamin 14 is a mixture of amino acids (total $694 \mathrm{mmol} / \mathrm{l}$ ) used for parenteral infusions and contains nine non-essential amino acids and all nine essential amino acids, including ( $\mathrm{mmol} / \mathrm{l})$ isoleucine (31.8), leucine (44.9) and valine (46.5). Approximately $1 \mathrm{ml}$ of blood was obtained every $5 \mathrm{~min}$ during the clamp to monitor plasma glucose and BCAA concentrations. Adjustment was based on experience and, in the case of glucose, with the aid of an $\operatorname{algorithm~}^{(47)}$.
During the last hour of the clamp, nine plasma samples were obtained (at 125, 135, 145, 155, 160, 165, 170, 175 and $180 \mathrm{~min}$ ) and frozen at $-80^{\circ} \mathrm{C}$ for later hormone and isotope enrichment analyses. During clamp 2 (post-supplementation), the glucose was maintained at the same concentration used for clamp 1 (pre-supplementation), whereas the BCAA were clamped at the fasting concentrations for the day.

For the muscle biopsy procedure, volunteers were treated similarly to those who underwent the clamp procedure with blood samples withdrawn at each of the monthly visits and with muscle biopsies taken after the 2-month introductory period and again after 9 months of FO supplementation. Muscle biopsies (300 mg) were obtained from the Vastus lateralis using the semi-open technique ${ }^{(48)}$, which involved local anaesthesia, a skin incision and muscle removal using alligator forceps (Weil-Blakesley conchotome); the samples were then frozen in liquid nitrogen and stored at $-80^{\circ} \mathrm{C}$.

\section{Sample processing and analyses}

Membrane phospholipids were extracted from the tissue (erythrocyte or muscle) using chloroform and methanol, with butylated hydroxytoluene present to prevent oxidation of fatty acids, and then separated by TLC $^{(49)}$ and analysed by GC (as methyl ester derivatives). In total, fourteen peaks were present for all the chromatograms and these were summed to estimate total and proportional fatty acid concentrations.

Concentrations of inflammatory IL- $1 \beta$, IL-6) and cardiovascular markers (soluble intracellular adhesion molecule and soluble vascular adhesion molecule) were analysed using a multiplex system (Millipore Corporation), and high sensitivity C-reactive protein (hsCRP) level was determined using a commercially available kit on a Konelab30 selective chemistry analyser (Thermo Fisher Scientific). Insulin and C-peptide concentrations were measured in duplicate using ELISA (Mercodia). Plasma lipid profiles were analysed using commercial kits on the Konelab30.

Enrichment (as tracer:tracee ratios) of D- $\left[6,6-{ }^{2} \mathrm{H}_{2}\right]$ glucose was determined as the penta-acetate derivative ${ }^{(50)}$, whereas enrichments of $\mathrm{L}_{\mathrm{L}}\left[1-{ }^{13} \mathrm{C}\right]$ leucine and $\mathrm{L}-\left[1-{ }^{13} \mathrm{C}\right]$ 4-methyl-2-oxo pentanoic acid (MOP) were quantified as described previously $^{(51)}$.

\section{Calculations}

Fasted endogenous glucose production (EGP) was calculated based on tracer dilution and a standard steady-state model ${ }^{(52)}$, with values for the last $20 \mathrm{~min}$ of collection used, where a temporal change of only $+1 \%$ in glucose tracer:tracee was observed over this period $(0.0316 v \cdot 0.0319 ; P<0.001)$, with no significant effect of type of oil and month of oil $\times$ month interaction. During normal high-insulin-euglycaemic clamp procedures, plasma amino acid concentrations decline and this may induce confounding metabolic effects that are avoided by the HIEGAA procedure ${ }^{(53)}$. In addition, the amount of amino acid infused to maintain euaminoacidaemia provides a measure of the sensitivity to the insulin challenge ${ }^{(37,39,53)}$, analogous to the situation with glucose. The dual clamp procedure requires 
separate calculations for glucose and amino acid (leucine) kinetics. During the last 60 min of the HIEGEAA clamp, glucose kinetics were determined based on Steele's model ${ }^{(54)}$ for nonsteady-state conditions with rate of appearance $(\mathrm{Ra})$ in plasma calculated using a previously published model $^{(52)}$ :

$$
\mathrm{Ra}(t)=\frac{I}{\operatorname{SAp}(t)}-\frac{\operatorname{pVG}(t)}{\operatorname{SAp}(t)} \frac{\mathrm{dSAp}(t)}{\mathrm{d} t}+\operatorname{SAg} \frac{\operatorname{GINF}(t)}{\operatorname{SAp}(t)}-\operatorname{GINF}(t)
$$

where $I$ is the rate of infusion of $\mathrm{D}-\left[6,6-{ }^{2} \mathrm{H}_{2}\right]$ glucose $(\mathrm{mmol} / \mathrm{min}), \mathrm{pV}$ is pool size $=0.65 \times 0.25 \times$ body weight based on analysis of similar subjects ${ }^{(50)}, \mathrm{G}(t)$ is the plasma glucose concentration $(\mathrm{mmol} / \mathrm{l}), \mathrm{dSAp}(t) / \mathrm{d} t$ is the rate of change in plasma enrichment of D- $\left[6,6-{ }^{2} \mathrm{H}_{2}\right]$ glucose $(\mathrm{mmol} / \mathrm{l}$ per min), SAg is enrichment of infusate (D-[6, $\left.6-{ }^{2} \mathrm{H}_{2}\right]$ glucose $\left.\mathrm{mmol} / \mathrm{l}\right)$ and $\operatorname{GINF}(t)$ is the exogenous glucose infusion rate $(\mathrm{mmol} / \mathrm{min})$. Rates of disappearance (Rd) were calculated using the same mo del approach ${ }^{(52)}$ with allowance for changes in pool sizes as follows:

$$
\operatorname{Rd}(t)=\frac{I}{\operatorname{SAp}(t)}-\frac{\mathrm{pVG}(t)}{\operatorname{SAp}(t)} \frac{\mathrm{dSAp}(t)}{\mathrm{d} t}+\operatorname{SAg} \frac{\operatorname{GINF}(t)}{\operatorname{SAp}(t)}-\mathrm{pV} \frac{\mathrm{dG}(t)}{\mathrm{d} t}
$$

where $\mathrm{pVdG}(t) / \mathrm{d}(t)$ is the rate of change in plasma glucose concentration ( $\mathrm{mmol} / \mathrm{l}$ per min). During the clamp procedure (insulin infusions), residual (non-suppressed) EGP was calculated as Ra minus infused glucose.

Protein (leucine) dynamics were estimated using a steadystate stochastic model with MOP chosen as the precursor pool $^{(55)}$ by the following equation:

$$
\mathrm{Rd}=\frac{\text { Infusion rate of labelled leucine }(\mu \mathrm{mol} / \mathrm{kg} \text { FFM per min })}{\text { tracer }: \text { tracee ratio MOP in plasma }}
$$

In the fasted state, $\mathrm{Rd}$ represents whole-body protein breakdown (WBPB). During the HIEGEAA clamp, the Rd of leucine represents the sum of leucine infused (quantified from the vamin 14 infusion) plus endogenous WBPB as altered by the infused insulin. Although at steady state Rd equals the $\mathrm{Ra}$, the latter could not be resolved into the two components of oxidative and non-oxidative (synthesis) rates. The homoeostatic model assessment of insulin resistance and $\beta$-cell reserve were calculated using an online calculator ${ }^{(56)}$.

\section{Statistical analysis and power calculations}

The primary outcome was altered insulin sensitivity and glycaemic control based on the HIEGEAA clamps. From literature sources, the between-subject spread was estimated as $15 \%$, so that a minimum of 12-16 volunteers were required per arm to detect an improvement of $18-20 \%$ in insulin sensitivity for glucose metabolism at a power of $90 \%$ for the $5 \%$ significance level. The secondary outcome was change in whole-body leucine $\mathrm{Rd}$, and based on our own and literature data the between-subject spread was $10 \%$, and thus to detect a $15 \%$ change at a power of $90 \%$ for the $5 \%$ significance level would require only nine subjects per group. For the pilot study, to look at differences between muscle and erythrocyte phospholipid contents, a $20 \%$ difference was detected at a power of $90 \%$ for the $5 \%$ significance level with four subjects based on $8 \%$ within-subject spread. Following initial recruitment, thirty-six volunteers were selected and paired between treatment arms on the basis of the amount of glucose infused during the $3 \mathrm{rd}$ hour of the HIEGEAA clamp. Three volunteers did not complete the study, and thus the final data were analysed as sixteen pairings with one unpaired subject (blind allocation to MO).

Data were analysed by fitting a mixed model using residual maximal likelihood with the statistical package GenStat (13th edition release 13.1, VSN International Ltd). For preintervention (baseline) data, pair was treated as a random effect, whereas the fixed effects were type of oil, sex and their interaction, with age and BMI as covariates. For the main analysis - namely, to compare the effect of FO with that of MO a random effects model was fitted with pair as a random effect, whereas sex, type of oil and their interaction were fitted as fixed effects. The pre-intervention value (month 0 ), age and BMI (both measured at month 0 ) were included as covariates. The effect of changes in body composition variables on markers of glycaemic control and insulin sensitivity were assessed by ANOVA through comparison of the differences between month 0 and 9 values with pair as the random effect, oil as the fixed effect and the difference in body composition change as a covariate. For all comparisons, $P<0.05$ was considered statistically significant; $P<0 \cdot 10$ was considered as a tendency. Data are presented as arithmetic means with either standard deviation or standard errors of the difference between means as appropriate.

\section{Results}

Volunteers randomly assigned to receive FO or MO were similar in demographics, plasma lipid profiles and plasma inflammatory markers (all $P>0 \cdot 10$; Table 1 ). Females had a higher body fat percentage than males ( $47.6 v .32 .3 \%$; SEM $1.8 \%$; $P<0.001)$. Females also had a greater hsCRP than males $(6 \cdot 1$ v. $2 \cdot 1 \mathrm{mg} / \mathrm{l}$; SEM $0.81 ; P=0 \cdot 002)$. Compliance was checked during the study period by capsule usage each month. A further check was made retrospectively after final data analysis for the subjects allocated FO, based on the changes in phospholipid composition of erythrocyte membranes (see below).

\section{Membrane phospholipid contents}

As expected, type of oil influenced the total $n$-3 PUFA content in erythrocyte membranes $(P<0.001$; Table 2$)$, with an increase in response to $\mathrm{FO}(+76 \%)$, whereas in the $\mathrm{MO}$ cohort it was unchanged (see below). These changes were also reflected in the increased composition of the individual $n$-3 PUFA (EPA, DPA and DHA; all $P<0 \cdot 001)$ for FO compared with MO. There was a corresponding decrease in both total and specific $n-6$ PUFA with FO compared with MO (all $P<0.001$; Table 2). The increase in $n-3$ PUFA and decrease in $n-6$ PUFA with FO balanced and, in consequence, the sum of $n+3$ and $n+6$ PUFA remained stable between $\mathrm{FO}$ and $\mathrm{MO}$ groups (online Supplementary Table S1). Total MUFA and SFA were both 
Table 1. Baseline demographics of subjects allocated to receive either fish oil (FO) or maize oil (MO) supplements for 9 months (Arithmetic means and standard deviations)

\begin{tabular}{|c|c|c|c|c|c|}
\hline & \multicolumn{2}{|c|}{$\mathrm{MO}(n 17)$ group } & \multicolumn{2}{|c|}{ FO $(n 16)$ group } & \multirow[b]{2}{*}{$P^{*}$} \\
\hline & Mean & SD & Mean & SD & \\
\hline $\operatorname{Sex}(M / F)$ & \multicolumn{2}{|c|}{$10 / 7$} & \multicolumn{2}{|c|}{$10 / 6$} & \\
\hline Age (years) $\dagger$ & & & & & 0.194 \\
\hline Mean & \multirow{2}{*}{\multicolumn{2}{|c|}{$\begin{array}{c}58 \cdot 1 \\
51-68\end{array}$}} & \multirow{2}{*}{\multicolumn{2}{|c|}{$\begin{array}{c}61 \cdot 8 \\
52-67\end{array}$}} & \\
\hline Range & & & & & \\
\hline Weight (kg) & $97 \cdot 2$ & $20 \cdot 8$ & 89.9 & $13 \cdot 7$ & 0.227 \\
\hline BMI $\left(\mathrm{kg} / \mathrm{m}^{2}\right)$ & $33 \cdot 8$ & $6 \cdot 7$ & $31 \cdot 8$ & $5 \cdot 2$ & 0.395 \\
\hline$\%$ Fatł & $39 \cdot 1$ & $9 \cdot 8$ & $37 \cdot 4$ & $11 \cdot 8$ & 0.551 \\
\hline Total cholesterol $(\mathrm{mmol} / \mathrm{l})$ & 4.75 & 1.02 & 4.68 & 0.91 & 0.841 \\
\hline HDL-cholesterol (mmol/l) & $1 \cdot 12$ & 0.32 & 0.99 & 0.40 & 0.175 \\
\hline LDL-cholesterol (mmol/l) & $2 \cdot 82$ & 0.99 & $2 \cdot 82$ & 0.83 & 0.984 \\
\hline TAG $(\mathrm{mmol} / \mathrm{l})$ & $1 \cdot 75$ & 0.99 & 1.68 & 0.99 & 0.847 \\
\hline $\mathrm{IL}-1 \beta(\mu \mathrm{g} / \mathrm{l})$ & 1.7 & 3.5 & 4.7 & $11 \cdot 2$ & 0.428 \\
\hline $\mathrm{IL}-6(\mu \mathrm{g} / \mathrm{I})$ & 1.6 & 1.6 & 11.9 & 36.8 & 0.297 \\
\hline sICAM-1 $(\mu \mathrm{g} / \mathrm{I})$ & 297 & 150 & 238 & 87 & 0.169 \\
\hline sVCAM-1 ( $\mu \mathrm{g} / \mathrm{l})$ & 1172 & 199 & 1249 & 318 & 0.438 \\
\hline hsCRP (mg/l)§ & 2.5 & $2 \cdot 0$ & 4.7 & $5 \cdot 6$ & 0.175 \\
\hline
\end{tabular}

M/F, male/female; sICAM, soluble intracellular cellular adhesion molecule-1; sVCAM-1, soluble vascular cellular adhesion molecule-1; hsCRP, high-sensitivity C-reactive peptide. * $P$ values for effect of allocation to type of oil from a random effects model with pairing as a random effect and sex $\times$ type of oil and their interaction as fixed effects.

† Sex effect $P=0.037$ (females younger than males with mean values 58.2 v. 60.0 years)

$\ddagger$ Sex effect $P<0.001$ (greater for females than males $47.6 \mathrm{v} .32 .2 \%$ ).

$\S$ Sex effect $P=0.002$ (greater for females than males $6.1 \mathrm{v} .21 .2 \mathrm{mg} / \mathrm{l}$ ).

Table 2. Effect of 9-month intervention of fish oil (FO) or maize oil (MO) on percentage contribution of various PUFA to total phospholipids in erythrocyte membranes

(Arithmetic means with their standard errors of the difference between means)

\begin{tabular}{|c|c|c|c|c|c|c|}
\hline & \multicolumn{2}{|c|}{ MO group ( $n$ 17) } & \multicolumn{2}{|c|}{ FO group (n 16) } & \multirow[b]{2}{*}{ SED* } & \multirow[b]{2}{*}{$P$ type of oil } \\
\hline & Month 0 & Month 9 & Month 0 & Month 9 & & \\
\hline Total $n$-3 PUFA† & $9 \cdot 3$ & $8 \cdot 8$ & $10 \cdot 0$ & $17 \cdot 6$ & 0.47 & $<0.001$ \\
\hline ALA & 0.3 & 0.2 & 0.2 & 0.3 & $0 \cdot 12$ & 0.752 \\
\hline EPA‡ & 1.9 & 1.6 & $2 \cdot 0$ & 5.9 & 0.32 & $<0.001$ \\
\hline DPA§ & 2.5 & 2.4 & $2 \cdot 8$ & 3.9 & 0.17 & $<0.001$ \\
\hline DHA & 4.9 & $4 \cdot 8$ & $5 \cdot 2$ & $7 \cdot 9$ & 0.26 & $<0.001$ \\
\hline Total n-6 PUFA & 31.9 & $33 \cdot 1$ & 31.6 & $25 \cdot 1$ & 1.25 & $<0.001$ \\
\hline C20 : 3n-6‡\| & $2 \cdot 0$ & $2 \cdot 0$ & $2 \cdot 2$ & 1.4 & 0.11 & $<0.001$ \\
\hline C20: 4n-6‡ & $15 \cdot 6$ & $16 \cdot 2$ & $16 \cdot 3$ & 11.6 & 0.95 & $<0.001$ \\
\hline C22:4n-6‡ & 2.5 & 2.7 & $2 \cdot 7$ & $1 \cdot 1$ & $0 \cdot 18$ & $<0.001$ \\
\hline
\end{tabular}

ALA, $a$-linolenic acid.

* For the main analysis, to compare the intervention of type of oil (FO v. MO), a random effects model was fitted with pair as a random effect, whereas sex, type of oil and their interaction were fitted as fixed effects. The pre-intervention value (month 0 ), age and BMI (both measured at month 0 ) were included as covariates. There were no significant differences for any variable at month 0 between the subjects allocated to either the FO or MO treatments, except for EPA where there was a sex-by-oil interaction $(P=0.050)$, with values lower for males compared with females allocated to MO, but with the situation reversed for those allocated to FO.

+ Total $n$-3 PUFA expressed as sum of EPA + DPA + DHA

$\ddagger$ Effect of age $(P<0.05)$.

$\S$ Effect of BMI $(P=0.014)$.

॥ Effect of $\operatorname{sex}(P=0.017)$ with average values for males greater than for females by $11 \%$.

unchanged by supplementation with either oil $(P>0 \cdot 10$; online Supplementary Table S1).

Before supplementation, for all the volunteers, the sum of EPA and DHA represented, on average, 6.9\% (range 4.6-9.7\%) of erythrocyte membrane phospholipids and this increased to 9.4\% (range 6.5-12.6\%) when DPA was included. For those volunteers who then received FO, the combined EPA, DPA plus DHA attained $>14 \% n-3$ PUFA enrichment in erythrocyte membrane phospholipids (range $14 \cdot 7-20 \cdot 3 \%$; Fig. 1) after 6 months of supplementation, but not when only EPA and DHA were combined (range 11.1-16.2\%). The proportion of $n$-3
PUFA in the erythrocyte membranes was greater in the FO group compared with the MO group from month 2 onwards $(P<0.001$; Fig. 1$)$. The changes in phospholipid composition in the erythrocyte membranes for the volunteers allocated to FO were in agreement with the compliance information obtained from capsule usage for this group.

For the pilot study, to compare phospholipid enrichments between membranes from erythrocytes and skeletal muscles, in the three volunteers who completed both muscle biopsies, the average $n$-3 PUFA in muscle membranes before FO supplementation was $2.4 \%$ (range $1.8-3.4 \%$ ) for EPA plus DHA and 


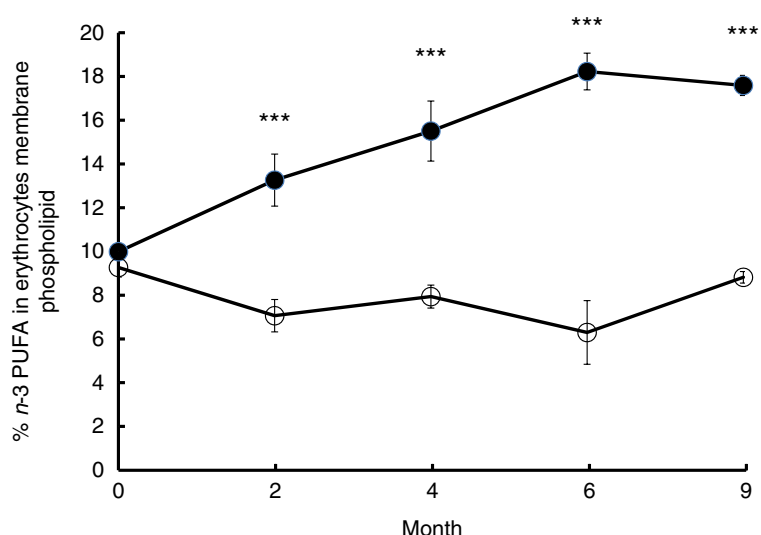

Fig. 1. Mean percentage, with their standard errors, of $n-3$ PUFA $(E P A+D H A+D P A)$ in phospholipids from erythrocyte membranes over the 9 -month intervention with either maize oil $(O, n 17)$ or fish oil $(\bullet, n 16)$. Values at the various time points are arithmetic means, with their standard errors.

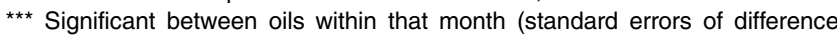
between type of oil within month 1.34), based on a random effects model analysis with volunteer and oil within volunteer as random effects and type of oil, month and their interaction as fixed effects $(P<0.001)$.

$3 \cdot 4 \%$ (range $2 \cdot 7-4 \cdot 7 \%$ ) when DPA was included (Fig. 2). FO increased the proportion of muscle membrane phospholipids to $6 \cdot 2 \%$ (range $5 \cdot 0-7 \cdot 9 \%$ ) as EPA plus DHA or $7.8 \%$ (range 6.0-9.7\%) when DPA was included. The muscle $n-3$ PUFA proportion as combined EPA, DHA and DPA was lower (28-59\%; SED $4.9 \% ; P<0.001)$ than that in erythrocytes before and after intervention (Fig. 2).

\section{Glucose metabolism}

For the primary outcome - assessment of the impact of FO on aspects of glycaemic control - changes in variables were considered in both the overnight fasted state (i.e. non-insulin stimulated) and during the HIEGEAA clamp (insulin-stimulated). In the fasted state, neither type of oil nor study duration altered the concentrations of plasma glucose or EGP (Table 3). Fasting insulin levels before intervention tended $(P=0.067)$ to be lower for those allocated to FO and over the period of FO supplementation tended $(P=0.053)$ to increase, but only to values similar to those in the MO group, which remained unchanged over the study period. A similar trend was observed for fasting C-peptide, where concentrations also tended $(P=0.093)$ to be lower for FO than MO before intervention, but during supplementation the $19 \%$ increase $(P=0.074)$ with FO raised values similar to those observed initially for the MO group (Table 3 )

During the final hour of each HIEGEAA clamp, plasma glucose concentrations were maintained within $5 \%$ of fasting values in sixty-four clamps (mean $\pm 2.0 \%$; SD $1.9 \%$; online Supplementary Table S2). On two other occasions, in different subjects, glucose was maintained at 8.4 and $8.7 \%$ of the target. In the insulin-stimulated state during the HIEGEAA clamp, neither total glucose disposal nor the amount of glucose (dextrose) infused differed between type of oil supplemented (Table 4), even when scaled against plasma insulin concentrations (Table 4). The residual (non-suppressed) EGP increased

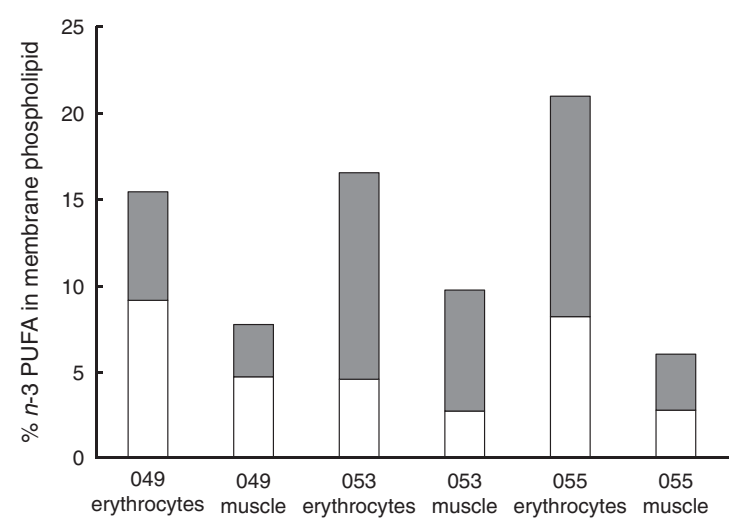

Volunteer and tissue

Fig. 2. Changes in the percentage of $n-3$ PUFA (EPA +DHA +DPA) in phospholipids from membranes of erythrocytes or muscle during the 9 months where three volunteers received fish oil (FO): pre-intervention ( $\square$, month 0 ), additional $n$-3 PUFA after 9 months of FO supplementation (

more for FO compared with $\mathrm{MO}(+40 \% v .8 \% ; P=0.050)$ during the 9 months of supplementation, with a similar tendency $(P=0.063)$ when scaled against plasma insulin. Nonetheless, even with these increases, the residual EGP still only represented a small proportion (average 15-20\%) of fasting EGP (Table 4) for both groups.

Endogenous insulin release, as assessed by C-peptide concentrations, continued during the last hour of the HIEGEAA clamp but overall was less than pre-clamp values (812 v. 946; SED 26.4; $P<0.001$ ), with no difference in response for type of oil (see Tables 3 and 4). The C-peptide during the HIEGEAA clamp responded differently $(P=0.028)$ between type of oil supplemented, with a slight decrease for MO (-5\%) over the 9 months while FO caused an increase $(+18 \%$; Table 4$)$. These subtle effects on endogenous insulin release were masked by the exogenous insulin infusion as this elevated plasma concentrations by $70 \mathrm{mU} / 1$, a 10-fold increase (range 2-50-fold) on fasting values, but did not differ $(P>0 \cdot 10)$ between type of oil (online Supplementary Table S2).

\section{Protein metabolism}

For the secondary objective - examination of the effect of FO on whole-body protein metabolism - there were no differences in plasma total BCAA in the overnight fasted state in response to supplementation with either FO or MO (Table 5). Similarly, fasting protein breakdown scaled for lean body mass did not differ either between type of oil or over the study duration, but values were greater $(+11 \% ; P=0.018)$ for females compared with males.

During the HIEGAA clamp, under the combined action of infused insulin, glucose and amino acids, the total amino acid disposal (based on MOP as precursor) differed between type of oil $(P=0.007)$ with a $9 \%$ increase for FO and a $10 \%$ decrease for MO over the 9 months of supplementation. This difference between type of oil was mainly due to altered endogenous (non-suppressed) protein breakdown $(P=0.001)$, with again an increase following $\mathrm{FO}(+10 \%)$ compared with a decrease 
Table 3. Effect of 9-month supplementation with either fish oil (FO) or maize oil (MO) on fasting glucose or hormones and endogenous glucose production (EGP)

(Arithmetic means with their standard errors of the difference between means)

\begin{tabular}{|c|c|c|c|c|c|c|}
\hline & \multicolumn{2}{|c|}{ MO group ( $n$ 17) } & \multicolumn{2}{|c|}{ FO group ( $n$ 16) } & \multirow[b]{2}{*}{ SED $^{*}$} & \multirow[b]{2}{*}{$P$ type of oil ${ }^{*}$} \\
\hline & Month 0 & Month 9 & Month 0 & Month 9 & & \\
\hline Fasting plasma glucose $(\mathrm{mmol} / \mathrm{l})$ & 6.03 & $6 \cdot 16$ & 5.97 & $6 \cdot 10$ & 0.255 & 0.874 \\
\hline Fasting insulin $(\mathrm{mU} / \mathrm{l}) \dagger$ & $14 \cdot 6$ & 14.4 & 9.5 & $13 \cdot 0$ & 1.82 & 0.043 \\
\hline Fasting C-peptide $(\mathrm{pmol} / \mathrm{l}) \dagger, \ddagger$ & 979 & 1002 & 823 & 979 & 81.4 & 0.067 \\
\hline HOMA2-IR $\dagger$ & 2.06 & 1.92 & 1.39 & 1.83 & 0.279 & 0.121 \\
\hline HOMA2- $\beta$ & $97 \cdot 2$ & 91.8 & $80 \cdot 3$ & 92.4 & 9.35 & 0.282 \\
\hline Fasting EGP (mg/kg FFM per min)† & $2 \cdot 60$ & 2.64 & 2.82 & 2.84 & 0.080 & 0.428 \\
\hline Fasting EGP scaled to insulin (mg/kg FFM per min per $\mathrm{mU}$ insulin)§ & 0.334 & 0.286 & 0.417 & 0.434 & 0.067 & 0.137 \\
\hline
\end{tabular}

HOMA2-IR, homoeostatic model assessment-insulin resistance; HOMA2- $\beta$, homoeostatic model assessment- $\beta$ cell function; FFM, fat-free mass.

* For the main analysis, to compare the intervention of type of oil (FO v. MO), a random effects model was fitted with pair as a random effect, whereas sex, type of oil and their interaction were fitted as fixed effects. The pre-intervention value (month 0 ), age and BMI (both measured at month 0 ) were included as covariates. For most variables, there were no significant differences at month 0 between the subjects allocated to either the FO or MO treatments.

$\dagger$ Tendency for effect of oil $(P<0.10)$ at month 0 with greater values for the MO group, except for fasting EGP where values for FO were greater.

$\ddagger$ Effect of $\operatorname{sex}(P=0.021)$ with values for males greater, on average, by $18 \%$.

$\S$ Effect of age $(P=0.026)$.

Table 4. Effect of 9-month supplementation with either fish oil (FO) or maize oil (MO) on parameters of glucose metabolism during high-insulin-euglycaemic-euaminoacidaemic clamps

(Arithmetic means with their standard errors of the difference between means)

\begin{tabular}{|c|c|c|c|c|c|c|}
\hline \multirow[b]{2}{*}{ Variables } & \multicolumn{2}{|c|}{ MO group $(n 17)$} & \multicolumn{2}{|c|}{ FO group $(n 16)$} & \multirow[b]{2}{*}{$\mathrm{SED}^{*}$} & \multirow[b]{2}{*}{$P$ type of oil ${ }^{\star}$} \\
\hline & Month 0 & Month 9 & Month 0 & Month 9 & & \\
\hline Total glucose infused (mg/kg FFM per min) & 5.39 & 5.48 & 5.89 & 5.78 & 0.627 & 0.791 \\
\hline Total glucose disposal (mg/kg FFM per min) & 5.81 & 6.02 & $6 \cdot 30$ & 6.46 & 0.642 & 0.937 \\
\hline Residual EGP (mg/kg FFM per min) & 0.42 & 0.45 & 0.41 & 0.57 & 0.064 & 0.042 \\
\hline$\%$ Residual EGP:fasting EGP & $16 \cdot 0$ & $16 \cdot 9$ & $15 \cdot 4$ & $20 \cdot 0$ & 2.52 & 0.099 \\
\hline Total glucose infused scaled for insulin (mg/kg FFM per min per mU) & 0.071 & 0.069 & 0.078 & 0.075 & 0.010 & 0.903 \\
\hline Total glucose disposal scaled for insulin (mg/kg FFM per min per mU) & 0.076 & 0.075 & 0.084 & 0.083 & 0.010 & 0.817 \\
\hline Residual EGP scaled for insulin (mg/kg FFM per min per mU) & 0.0046 & 0.0050 & 0.0054 & 0.0071 & 0.0008 & 0.055 \\
\hline C-peptide during the $3 \mathrm{rd}$ hour of the clamp $(\mathrm{pmol} / \mathrm{l})$ & 875 & 831 & 704 & 834 & 79.4 & 0.023 \\
\hline
\end{tabular}

FFM, fat-free mass; EGP, endogenous glucose production.

* For the main analysis, to compare the intervention of type of oil (FO v. MO), a random effects model was fitted with pair as a random effect, whereas sex, type of oil and their interaction were fitted as fixed effects. The pre-intervention value (month 0 ), age and BMI (both measured at month 0 ) were included as covariates. There were no significant differences for any variable at month 0 between the subjects allocated to either the FO or MO treatments.

Table 5. Effect of 9-month supplementation with either fish oil (FO) or maize oil (MO) on infusion and plasma concentrations of branched-chain amino acids and estimates of protein metabolism based on leucine kinetics in either the fasting state or during hyperinsulinemic-euglycaemic-euaminoacidaemic (HIEGEAA) clamps

(Arithmetic means with their standard errors of the difference between means)

\begin{tabular}{|c|c|c|c|c|c|c|}
\hline & \multicolumn{2}{|c|}{ MO group $(n 17)$} & \multicolumn{2}{|c|}{ FO group $(n 16)$} & \multirow[b]{2}{*}{ SED $^{*}$} & \multirow[b]{2}{*}{$P$ type of oil } \\
\hline & Month 0 & Month 9 & Month 0 & Month 9 & & \\
\hline Fasting BCAA concentration $(\mu \mathrm{mol} / \mathrm{l})$ & 348 & 343 & 360 & 360 & $18 \cdot 8$ & 0.811 \\
\hline Fasting protein breakdown $(\mu \mathrm{mol} / \mathrm{min}$ per $\mathrm{kg} \mathrm{FFM}) \dagger, \S$ & $2 \cdot 75$ & $2 \cdot 68$ & 2.57 & 2.64 & 0.093 & $0 \cdot 135$ \\
\hline Leucine infused as vamin $14(\mu \mathrm{mol} / \mathrm{min}$ per $\mathrm{kg}$ FFM $) \ddagger$ & 0.59 & 0.53 & 0.60 & 0.64 & 0.068 & 0.237 \\
\hline Total protein disposal $(\mu \mathrm{mol} / \mathrm{min}$ per $\mathrm{kg} \mathrm{FFM}) \dagger$ & 2.46 & $2 \cdot 19$ & $2 \cdot 39$ & $2 \cdot 62$ & 0.144 & 0.007 \\
\hline Endogenous protein breakdown $(\mu \mathrm{mol} / \mathrm{min}$ per kg FFM $) \dagger$ & 1.90 & 1.69 & 1.83 & 2.02 & 0.093 & 0.002 \\
\hline$\%$ EPB:FPB & 69.4 & 63.5 & 71.6 & $77 \cdot 9$ & 4.05 & 0.005 \\
\hline
\end{tabular}

BCAA, combined branched-chain amino acids (isoleucine, leucine and valine); FFM, fat-free mass; EPB, endogenous protein breakdown during the HIEGEAA clamp; FBP, fasting protein breakdown.

* For the main analysis, to compare the intervention of type of oil (FO v. MO), a random effects model was fitted with pair as a random effect, whereas sex, type of oil and their interaction were fitted as fixed effects. The pre-intervention value (month 0 ), age and BMI (both measured at month 0 ) were included as covariates. There were no significant differences for any variable at month 0 between the subjects allocated to either the FO or MO treatments.

$\dagger$ Estimates of protein metabolism based on plasma enrichments of $\left[1-{ }^{13} \mathrm{C} 4\right.$-methyl-2-oxo pentanoic acid], the oxo-acid of leucine, as the precursor pool.

‡ Leucine present at $44.9 \mathrm{mmol} / \mathrm{l}$ in vamin 14 (total amino acids present at $694 \mathrm{mmol} / \mathrm{l}$ ).

$\S$ Effect of sex $(P=0.018)$, females greater than males $(2.83$ v. $2.55 \mu \mathrm{mol} / \mathrm{min}$ per $\mathrm{kg}$ FFM, SED 0.125$)$. 
( $-11 \%$ ) with MO (Table 5). In consequence, endogenous protein breakdown during the clamp expressed as a proportion of fasting protein breakdown differed $(P<0.001)$ with type of oil used as supplement, with an increase when FO was supplied compared with a decrease with the MO intervention (Table 5).

\section{Responses in body composition, plasma lipid profile and inflammatory and cardiovascular markers}

Most of the body composition parameters were not altered by type of oil provided as supplement (online Supplementary Table S3), except that both groups showed a small increase over time in percent fat mass $(+1.2$ and $+1.4 \%$ for MO and FO, respectively, $P_{\text {trend }}=0.057$ for month) and total fat mass $(+1.9 \mathrm{~kg}$ for both $\mathrm{MO}$ and $\mathrm{FO}, P=0.014$ for month). This probably relates to the additional energy provided as the oil supplements (59 MJ (14 Mcal) over study duration). In contrast, lean body mass $(\mathrm{kg})$ was unaltered by intervention with either oil (online Supplementary Table S3). There were no impacts $(P>0.05)$ of changes in either body weight or total body fat on the amount of glucose infused during the clamp, total glucose disposal (Rd) or residual (non-suppressed) EGP. HDL-cholesterol increased (17\%) with FO and decreased $(-5 \%)$ with MO $(P=0.085$ for type of oil; online Supplementary Table S4). Although TAG were unaffected by oil supplementation (online Supplementary Table S4), this may have been influenced by those volunteers on statin medication. For the volunteers who were not on statin medication, those in the FO group ( $n$ 10) had a percentage decrease during the supplementation while those on MO $(n 10)$ increased $(-17 \cdot 4 v$. $+20.8 \%$; SED $16 \cdot 6 ; \quad P=0.043)$. There were no changes in inflammatory markers or the two adhesion molecules between the types of oil provided as the supplement (online Supplementary Table S5).

\section{Discussion}

Previous studies on the impact of FO supplements on insulin sensitivity and glycaemic control have produced inconsistent outcomes. A small number reported positive effects, for example $^{(4,15)}$, whereas a similar number showed a deterioration in glycaemic control, for example ${ }^{(16,17)}$. The majority of studies, however, reported either no or inconsistent responses, for example ${ }^{(5,37)}$. This provides a dilemma for nutritionists as to whether to recommend FO as an effective dietary supplement to people with impaired glycaemic control or patients with type 2 diabetes controlled by diet and lifestyle changes ${ }^{(38)}$. The various human studies involved a wide range of both dose of FO $(1.8-7.5 \mathrm{~g} / \mathrm{d})$ and study duration (2-24 weeks), but data from piglets and steers have suggested that an enrichment of the muscle membrane phospholipid to $14 \%$ of $n$-3 PUFA is required to effect a change in insulin sensitivity linked to glucose and protein metabolisms ${ }^{(6,40)}$. Achievement of such membrane enrichments in humans would necessitate either a high dose of FO for moderate duration or a moderate dose for long duration, and few of the published studies have achieved these requirements. Therefore, the present study sought to determine whether a dose $(3.9 \mathrm{~g} / \mathrm{d})$, between the upper limits recommended in the USA and Europe ${ }^{(43,44)}$, given over 9 months would change glycaemic control and (or) insulin sensitivity in humans with impaired glucose regulation.

Despite this dose and length of time of supplementation with $n$-3 PUFA, there was no improvement in either insulin sensitivity or regulation of glycaemia. The observed small increase in residual EGP following the FO intervention was insufficient to impact markedly on overall glucose disposal. This raises the following question: how can the present findings be reconciled with the epidemiological associations reported for the Inuit or with the animal studies where positive health benefits of FO are often reported?

The phospholipid content of erythrocyte membranes comprise $11 \% n$-3PUFA in Inuit who consume $\geq 32 \%$ of their diet from traditional foods ${ }^{(57)}$ and reached $20 \%$ in muscles from animal studies where improved insulin sensitivity was achieved $^{(6,39)}$. In the present study, the phospholipid content as combined EPA, DPA and DHA in erythrocyte membranes increased to a mean of $17 \%$ after 9 months and all the subjects attained $>14 \% n-3$ PUFA. Similar erythrocyte membrane enrichments were observed in the small biopsy cohort, but these subjects only achieved a maximum of $9.7 \%$ (mean $7.8 \%$ ) in muscle membrane phospholipids, similar to values reported with just 8 weeks of supplementations ${ }^{(37,42)}$. These low values may partly explain why neither improved glycaemic control nor insulin sensitivity occurred after the FO intervention in the earlier ${ }^{(37,42)}$ and present studies. On the basis of the current findings, however, achievement in humans of muscle membrane $n-3$ PUFA enrichments postulated to result in improved insulin sensitivity in animal studies may be difficult under experimental, or normal lifestyle, conditions within the safe recommended intakes for the USA and Europe.

Furthermore, direct comparison with the original healthrelated findings from the Inuit population ${ }^{(8,9)}$ is difficult because sources of $n$ - 3 PUFA in the Inuit diet include marine mammals, the oil of which differs in phospholipid composition to that of fish, but that has equal or superior health-related properties ${ }^{(7,58)}$. An additional concern is that in animal studies, where improvements in either glucose and (or) protein metabolism have been reported, the doses of dietary $n$ - 3 PUFA (expressed as $\mathrm{g} / \mathrm{d}$ per kg body weight) have been high - for example, in rats $0 \cdot 75-2 \cdot 7 \mathrm{~g}^{(59,60)}$, in piglets $5 \cdot 2 \mathrm{~g}^{(6)}$ and in steers $0 \cdot 20 \mathrm{~g}^{(39)}$. In this study, the average dose of $n$-3 PUFA was $0.03 \mathrm{~g} / \mathrm{kg}$ body weight, and thus whether $14 \% n$-3 PUFA in muscle membranes of human is possible under Western dietary conditions and recommended safety limits has yet to be determined. This may be further complicated if humans are similar to sea mammals and limit $n-3$ PUFA in muscle membranes to considerably below the amounts present in the diet ${ }^{(61)}$.

The aetiology of obesity and type 2 diabetes are thought to be due, in part, to inflammation ${ }^{(5,15,62,63)}$, and some of the beneficial effects of $n-3$ PUFA have been ascribed to anti-inflammatory properties ${ }^{(4,5,15,64,65)}$. Nonetheless, no changes in inflammatory markers were demonstrated in the present study. This may reflect the fact that, although the population studied were 'at risk' of type 2 diabetes, they were relatively healthy with a low status for baseline inflammatory markers. 
Other studies have also failed to demonstrate a clear association between $n$-3 PUFA intake or status and glycaemic control $^{(37,42,66)}$ or with inflammation in healthy subjects ${ }^{(42,66)}$ but have done so for subjects with metabolic syndrome ${ }^{(67)}$. The $n-3$ PUFA supplementation did not alter the concentration of LDLcholesterol, which has been a concern in some studies ${ }^{(17,68)}$, whereas HDL-cholesterol concentration increased over the course of the study. Although $n-3$ PUFA has been demonstrated in the past to lower plasma triglyceride concentrations ${ }^{(69)}$, this only occurred for the current volunteers who were not on statin medication. Statins have been shown to lower triglyceride levels ${ }^{(70)}$ and this may have restricted the ability to allow further reductions with $\mathrm{FO}$.

In contrast to the findings for glucose metabolism, wholebody protein kinetics were altered as a result of the high-dose long-term $n$-3 PUFA supplementation, but this only occurred during the insulin-stimulated state, not the basal (fasting) condition. These data support the findings from a number of recent studies - for example, muscle protein synthesis in both young and middle-aged or elderly subjects was increased following FO supplementation ${ }^{(42,42)}$ in the insulin-stimulated, but not basal, state. This has parallels with the situation in both neonatal pigs ${ }^{(71)}$ and elderly humans ${ }^{(72)}$, where elevated insulin concentrations stimulated muscle protein gain at otherwise similar nutritional inputs. Furthermore, the increase in protein disposal during the HIEGEAA clamp in the current subjects who received FO agrees with findings in growing farm animals $^{(6,39,40)}$. Nonetheless, changes in protein dynamics may not necessarily translate into improved net protein anabolism for example, despite the observed increases in muscle protein synthesis and whole-body protein disposal in the insulinstimulated state, FO supplementation did not improve growth rates or $\mathrm{N}$ retention in pigs ${ }^{(6)}$, steers ${ }^{(39,40)}$ or rats ${ }^{(59)}$ compared with control animals. In addition, no changes in lean body mass were observed in the present study during the 9-month supplementation with FO. Such lack of responses in protein gain may relate to metabolism only being stimulated when insulin concentrations are elevated - for example, in the few hours after each large meal. For the rest of the day, effectively a basal state exists and this may mitigate, or even counterbalance, the transient effects of the insulin-stimulated condition. The situation may be different in net catabolic states, however, as reduced rate of loss of either body weight or lean mass have been reported for some patients newly diagnosed with various cancers when given EPA as a supplement $^{(73)}$.

Limitations of the study include the small number of subjects. This was counterbalanced by the use of a pairing procedure to match specific initial metabolic parameters between the two groups. With the considerable number of measurements made, it was not possible to match all of them, however, and initial numerical differences between groups in fasting insulin and C-peptide existed. Total body fat also increased in both groups over the study duration and may have reduced any response in glycaemic control and insulin sensitivity as both parameters have been reported to correlate negatively with increased $\mathrm{BMI}^{(74)}$, although not in all studies ${ }^{(75)}$. Although the volunteers exhibited impaired glycaemic control, their levels of inflammatory markers were similar to that reported for healthy subjects and the treatment outcome may be different in populations with elevated inflammatory status. No measures of tissue protein synthesis were performed, and thus it was not possible to confirm the increases in muscle protein synthesis following FO supplementation as reported by others ${ }^{(37,42)}$. The pilot study to compare phospholipid contents in erythrocyte and muscle membranes only had three volunteers who completed the study, but the difference in enrichments were large and statistically robust. Strengths of the study include the near-prescription dose used and the longer period of intervention than that reported for many studies. This allows for maximum increases in membrane phospholipid content under safe conditions. The use of HIEGEAA clamp procedures also provided a well-accepted measure of insulin sensitivity and glycaemic control. Measurement of lean body mass showed that the insulin-stimulated changes in whole-body protein metabolism may not necessarily translate into improved net anabolism, although this outcome may be different in net catabolic states, including age-related sarcopenia, or for intervention periods longer than 9 months.

In summary, this study has not established any change in glucose metabolism following prolonged FO supplementation. Although there were responses of FO supplementation on protein dynamics, whether this translates into improved protein anabolism in other populations remains unclear and requires further investigation.

\section{Acknowledgements}

The authors thank Vivien Buchan, Susan Anderson, Graham Calder, Susan Moir and David Bremner for their various analytical expertise. Lynn Walker, Norma Alexander and Frances Rentoul provided invaluable support during the HIEGEAA clamps. The authors also thank Lesley Hall for performing the muscle biopsies. Anne-Sophie DaCosta and KenWei Lee performed data analyses as part of student projects. The support of EPAX AS and their scientific advisor Morten Bryhn for the supply of the FO and MO capsules is gratefully recognised.

This work was funded as part of the core grant from Rural and Environment Science and Analytical Services Division of the Scottish Government to the Rowett Institute of Nutrition and Health, University of Aberdeen and to Biomathematics and Statistics Scotland, Aberdeen. Neither the funding body nor EPAX AS had any role in the design and conduct of the study; collection, management, analysis and interpretation of the data; or preparation, review and approval of the manuscript.

The author's responsibilities were as follows: M. C. T., G. E. L. and L. F. C. designed the research and were involved in subject recruitment, data collection, data analyses and manuscript preparation; P. A. and D. W. M. P. supervised clinical aspects; S. C. M. was involved in subject recruitment and management; S. C. M. conducted the initial clamps; G. W. H. and G. H. provided statistical and modelling support and controlled the double-blind procedure; F. T. supervised lipid analyses and was involved in manuscript preparation.

The authors declare that there are no conflicts of interest. 


\section{Supplementary material}

For supplementary material/s referred to in this article, please visit http://dx.doi.org/doi:10.1017/S0007114515004274

\section{References}

1. American Diabetes Association (2014) National Diabetes Statistics Report, 2014. Alexandria, VA: ADA.

2. Defronzo RA \& Tripathy D (2009) Skeletal muscle insulin resistance is the primary defect in type 2 diabetes. Diabetes Care 32, Suppl 2, S157-S163.

3. Helmrich SP, Ragland DR, Leung RW, et al. (1991) Physical activity and reduced occurrence of non-insulin-dependent diabetes mellitus. $N$ Engl J Med 325, 147-152.

4. Ramel A, Martinez A, Kiely M, et al. (2008) Beneficial effects of long-chain $n$ - 3 fatty acids included in an energy-restricted diet on insulin resistance in overweight and obese European young adults. Diabetologia 51, 1261-1268.

5. Krebs JD, Browning LM, McLean NK, et al. (2006) Additive benefits of long-chain $n-3$ polyunsaturated fatty acids and weight-loss in the management of cardiovascular disease risk in overweight hyperinsulinaemic women. Int J Obes (Lond) 30, 1535-1544.

6. Bergeron K, Julien P, Davis TA, et al. (2007) Long-chain n-3 fatty acids enhance neonatal insulin-regulated protein metabolism in piglets by differentially altering muscle lipid composition. J Lipid Res 48, 2396-2410.

7. Zhu FS, Liu S, Chen XM, et al. (2008) Effects of $n-3$ polyunsaturated fatty acids from seal oils on nonalcoholic fatty liver disease associated with hyperlipidemia. World J Gastroenterol 14, 6395-6400.

8. Mouratoff GJ, Carroll NV \& Scott EM (1967) Diabetes mellitus in Eskimos. JAMA 199, 107-112.

9. Mouratoff GJ \& Scott EM (1973) Diabetes mellitus in Eskimos after a decade. JAMA 226, 1345-1346.

10. Murphy NJ, Schraer CD, Thiele MC, et al. (1995) Dietary change and obesity associated with glucose intolerance in Alaska Natives. J Am Diet Assoc 95, 676-682.

11. Storlien LH, Kraegen EW, Chisholm DJ, et al. (1987) Fish oil prevents insulin resistance induced by high-fat feeding in rats. Science 237, 885-888.

12. Popp-Snijders C, Schouten JA, Heine RJ, et al. (1987) Dietary supplementation of omega-3 polyunsaturated fatty acids improves insulin sensitivity in non-insulin-dependent diabetes. Diabetes Res 4, 141-147.

13. Fasching P, Ratheiser K, Waldhausl W, et al. (1991) Metabolic effects of fish-oil supplementation in patients with impaired glucose tolerance. Diabetes 40, 583-589.

14. Browning LM, Krebs JD, Moore CS, et al. (2007) The impact of long chain $n$-3 polyunsaturated fatty acid supplementation on inflammation, insulin sensitivity and CVD risk in a group of overweight women with an inflammatory phenotype. Diabetes Obes Metab 9, 70-80.

15. Rasic-Milutinovic Z, Perunicic G, Pljesa S, et al. (2007) Effects of $n-3$ PUFAs supplementation on insulin resistance and inflammatory biomarkers in hemodialysis patients. Ren Fail 29, 321-329.

16. Glauber H, Wallace P, Griver K, et al. (1988) Adverse metabolic effect of omega-3 fatty acids in non-insulin-dependent diabetes mellitus. Ann Intern Med 108, 663-668.

17. Schectman G, Kaul S \& Kissebah AH (1988) Effect of fish oil concentrate on lipoprotein composition in NIDDM. Diabetes 37, 1567-1573.
18. Vessby B \& Boberg M (1990) Dietary supplementation with $n$-3 fatty acids may impair glucose homeostasis in patients with non-insulin-dependent diabetes mellitus. J Intern Med 228, 165-171.

19. Zambon S, Friday KE, Childs MT, et al. (1992) Effect of glyburide and omega 3 fatty acid dietary supplements on glucose and lipid metabolism in patients with non-insulin-dependent diabetes mellitus. Am J Clin Nutr 56, 447-454.

20. Mostad IL, Bjerve KS, Bjorgaas MR, et al. (2006) Effects of $n-3$ fatty acids in subjects with type 2 diabetes: reduction of insulin sensitivity and time-dependent alteration from carbohydrate to fat oxidation. Am J Clin Nutr 84, 540-550.

21. Giacco R, Cuomo V, Vessby B, et al. (2007) Fish oil, insulin sensitivity, insulin secretion and glucose tolerance in healthy people: is there any effect of fish oil supplementation in relation to the type of background diet and habitual dietary intake of n-6 and n-3 fatty acids? Nutr Metab Cardiovasc Dis 17, 572-580.

22. Vessby B, Uusitupa M, Hermansen K, et al. (2001) Substituting dietary saturated for monounsaturated fat impairs insulin sensitivity in healthy men and women: the KANWU study. Diabetologia 44, 312-319.

23. Skulas-Ray AC, Kris-Etherton PM, Harris WS, et al. (2011) Dose-response effects of omega-3 fatty acids on triglycerides, inflammation, and endothelial function in healthy persons with moderate hypertriglyceridemia. Am J Clin Nutr 93, 243-252.

24. Sirtori CR, Paoletti R, Mancini M, et al. (1997) n-3 Fatty acids do not lead to an increased diabetic risk in patients with hyperlipidemia and abnormal glucose tolerance. Italian Fish Oil Multicenter study. Am J Clin Nutr 65, 1874-1881.

25. Griffin MD, Sanders TA, Davies IG, et al. (2006) Effects of altering the ratio of dietary $n-6$ to $n-3$ fatty acids on insulin sensitivity, lipoprotein size, and postprandial lipemia in men and postmenopausal women aged 45-70 y: the OPTILIP Study. Am J Clin Nutr 84, 1290-1298.

26. Kabir M, Skurnik G, Naour N, et al. (2007) Treatment for 2 mo with $n-3$ polyunsaturated fatty acids reduces adiposity and some atherogenic factors but does not improve insulin sensitivity in women with type 2 diabetes: a randomized controlled study. Am J Clin Nutr 86, 1670-1679.

27. Luo J, Rizkalla SW, Vidal H, et al. (1998) Moderate intake of n-3 fatty acids for 2 months has no detrimental effect on glucose metabolism and could ameliorate the lipid profile in type 2 diabetic men. Results of a controlled study. Diabetes Care 21, 717-724.

28. McManus RM, Jumpson J, Finegood DT, et al. (1996) A comparison of the effects of $n-3$ fatty acids from linseed oil and fish oil in well-controlled type II diabetes. Diabetes Care 19, 463-467.

29. Woodman RJ, Mori TA, Burke V, et al. (2002) Effects of purified eicosapentaenoic and docosahexaenoic acids on glycemic control, blood pressure, and serum lipids in type 2 diabetic patients with treated hypertension. Am J Clin Nutr $\mathbf{7 6}$, 1007-1015.

30. Puhakainen I, Ahola I \& Yki-Jarvinen H (1995) Dietary supplementation with $n-3$ fatty acids increases gluconeogenesis from glycerol but not hepatic glucose production in patients with non-insulin-dependent diabetes mellitus. Am J Clin Nutr 61, 121-126

31. Pelikanova T, Kohout M, Valek J, et al. (1993) Metabolic effects of omega-3 fatty acids in type 2 (non-insulin-dependent) diabetic patients. Ann N Y Acad Sci 683, 272-278.

32. Stacpoole PW, Alig J, Ammon L, et al. (1989) Dose-response effects of dietary marine oil on carbohydrate and lipid metabolism in normal subjects and patients with hypertriglyceridemia. Metabolism 38, 946-956. 
33. Connor WE, Prince MJ, Ullmann D, et al. (1993) The hypotriglyceridemic effect of fish oil in adult-onset diabetes without adverse glucose control. Ann N Y Acad Sci $\mathbf{6 8 3}$, 337-340.

34. Annuzzi G, Rivellese A, Capaldo B, et al. (1991) A controlled study on the effects of $n-3$ fatty acids on lipid and glucose metabolism in non-insulin-dependent diabetic patients. Atherosclerosis 87, 65-73.

35. Boberg M, Pollare T, Siegbahn A, et al. (1992) Supplementation with $n$-3 fatty acids reduces triglycerides but increases PAI-1 in non-insulin-dependent diabetes mellitus. Eur J Clin Invest 22, 645-650.

36. Borkman M, Chisholm DJ, Furler SM, et al. (1989) Effects of fish oil supplementation on glucose and lipid metabolism in NIDDM. Diabetes 38, 1314-1319.

37. Smith GI, Atherton P, Reeds DN, et al. (2011) Dietary omega-3 fatty acid supplementation increases the rate of muscle protein synthesis in older adults: a randomized controlled trial. Am J Clin Nutr 93, 402-412.

38. Akinkuolie AO, Ngwa JS, Meigs JB, et al. (2011) Omega-3 polyunsaturated fatty acid and insulin sensitivity: a meta-analysis of randomized controlled trials. Clin Nutr 30, 702-707.

39. Gingras AA, White PJ, Chouinard PY, et al. (2007) Long-chain omega-3 fatty acids regulate bovine whole-body protein metabolism by promoting muscle insulin signaling to the Akt-mTOR-S6K1 pathway and insulin sensitivity. J Physiol 579, 269-284.

40. Fortin M, Julien P, Couture Y, et al. (2010) Regulation of glucose and protein metabolism in growing steers by longchain $n-3$ fatty acids in muscle membrane phospholipids is dose-dependent. Animal 4, 89-101.

41. Flock MR, Harris WS \& Kris-Etherton PM (2013) Long-chain omega-3 fatty acids: time to establish a dietary reference intake. Nutr Rev 71, 692-707.

42. Smith GI, Atherton P, Reeds DN, et al. (2011) Omega-3 polyunsaturated fatty acids augment the muscle protein anabolic response to hyperinsulinaemia-hyperaminoacidaemia in healthy young and middle-aged men and women. Clin Sci (Lond) 121, 267-278.

43. Food and Nutrition Board (2005) Dietary Reference Intakes for Energy, Carbohydrate, Fiber, Fat, Fatty Acids, Cholesterol, Protein, and Amino Acids (Macronutrients). Washington, DC: The National Academies Press.

44. EFSA Panel on Dietetic Products Nutrition and Allergies (NDA) (2012) Scientific Opinion related to the Tolerable Upper Intake Level of eicosapentaenoic acid (EPA), docosahexaenoic acid (DHA) and docosapentaenoic acid (DPA). EFSA J 10, 2815.

45. Johnstone AM, Horgan GW, Murison SD, et al. (2008) Effects of a high-protein ketogenic diet on hunger, appetite, and weight loss in obese men feeding ad libitum. Am J Clin Nutr 87, 44-55.

46. Beckett PR, Hardin DS, Davis TA, et al. (1996) Spectrophometric assay for measuring branched-chain amino acid concentrations: application for measuring the sensitivity of protein metabolism to insulin. Anal Biochem 240, 48-53.

47. Defronzo RA, Tobin JD \& Andres R (1979) Glucose clamp technique: a method for quantifying insulin secretion and resistance. Am J Physiol 237, E214-E223.

48. Henriksson KG (1979) "Semi-open" muscle biopsy technique. A simple outpatient procedure. Acta Neurol Scand 59, 317-323.

49. Bligh EG \& Dyer WJ (1959) A rapid method of total lipid extraction and purification. Can J Biochem Physiol 37, 911-917.
50. Lobley GE, Holtrop G, Bremner DM, et al. (2013) Impact of short term consumption of diets high in either non-starch polysaccharides or resistant starch in comparison with moderate weight loss on indices of insulin sensitivity in subjects with metabolic syndrome. Nutrients 5, 2144-2172.

51. Calder AG \& Smith A (1988) Stable isotope ratio analysis of leucine and ketoisocaproic acid in blood plasma by gas chromatography/mass spectrometry. Use of tertiary butyldimethylsilyl derivatives. Rapid Commum Mass Spectrom 2, $14-16$.

52. Finegood DT, Bergman RN \& Vranic M (1987) Estimation of endogenous glucose production during hyperinsulinemiceuglycemic glucose clamps. Comparison of unlabeled and labeled exogenous glucose infusates. Diabetes 36, 914-924.

53. Barazzoni R, Kiwanuka E, Zanetti $\mathrm{M}$, et al. (2003) Insulin acutely increases fibrinogen production in individuals with type 2 diabetes but not in individuals without diabetes. Diabetes 52, 1851-1856.

54. Steele R (1959) Influences of glucose loading and of injected insulin on hepatic glucose output. Ann N Y Acad Sci 82, 420-430.

55. Matthews DE, Schwarz HP, Yang RD, et al. (1982) Relationship of plasma leucine and alpha-ketoisocaproate during a $\mathrm{L}-\left[1-{ }^{13} \mathrm{C}\right]$ leucine infusion in man: a method for measuring human intracellular leucine tracer enrichment. Metabolism $\mathbf{3 1}$, $1105-1112$

56. Diabetes Trial Unit (2014) The Oxford Centre for Diabetes, Endocrinology and Metabolism. www.dtu.ox.ac.uk/homa calculator/index.php (accessed September 2014).

57. Bersamin A, Luick BR, King IB, et al. (2008) Westernizing diets influence fat intake, red blood cell fatty acid composition, and health in remote Alaskan Native communities in the Center for Alaska Native Health Study. J Am Diet Assoc 108, 266-273.

58. Mann NJ, O'Connell SL, Baldwin KM, et al. (2010) Effects of seal oil and tuna-fish oil on platelet parameters and plasma lipid levels in healthy subjects. Lipids 45, 669-681.

59. Kamolrat T, Gray SR \& Thivierge MC (2013) Fish oil positively regulates anabolic signalling alongside an increase in wholebody gluconeogenesis in ageing skeletal muscle. Eur J Nutr 52, 647-657.

60. Storlien LH, Jenkins AB, Chisholm DJ, et al. (1991) Influence of dietary fat composition on development of insulin resistance in rats. Relationship to muscle triglyceride and omega-3 fatty acids in muscle phospholipid. Diabetes 40, 280-289.

61. Harris WS \& Schmitt TL (2014) Unexpected similarity in RBC DHA and AA levels between bottlenose dolphins and humans. Prostaglandins Leukot Essent Fatty Acids 90 , $55-59$.

62. Muller S, Martin S, Koenig W, et al. (2002) Impaired glucose tolerance is associated with increased serum concentrations of interleukin 6 and co-regulated acute-phase proteins but not TNF-alpha or its receptors. Diabetologia 45, 805-812.

63. Herder C, Baumert J, Thorand B, et al. (2006) Chemokines as risk factors for type 2 diabetes: results from the MONICA/ KORA Augsburg study, 1984-2002. Diabetologia 49, 921-929.

64. Todoric J, Loffler M, Huber J, et al. (2006) Adipose tissue inflammation induced by high-fat diet in obese diabetic mice is prevented by $n-3$ polyunsaturated fatty acids. Diabetologia 49, 2109-2119.

65. Farzaneh-Far R, Harris WS, Garg S, et al. (2009) Inverse association of erythrocyte $n-3$ fatty acid levels with inflammatory biomarkers in patients with stable coronary artery disease: the Heart and Soul study. Atherosclerosis 205, 538-543.

66. Mahendran Y, Agren J, Uusitupa M, et al. (2014) Association of erythrocyte membrane fatty acids with changes in glycemia and risk of type 2 diabetes. Am J Clin Nutr 99, 79-85. 
67. Robinson LE \& Mazurak VC (2013) n-3 Polyunsaturated fatty acids: relationship to inflammation in healthy adults and adults exhibiting features of metabolic syndrome. Lipids 48, 319-332.

68. Harris WS (1997) n-3 Fatty acids and serum lipoproteins: human studies. Am J Clin Nutr 65, 1645S-1654S.

69. Sacks FM, Stone PH, Gibson CM, et al. (1995) Controlled trial of fish oil for regression of human coronary atherosclerosis. HARP Research Group. J Am Coll Cardiol 25, 1492-1498.

70. Jones PH, Davidson MH, Stein EA, et al. (2003) Comparison of the efficacy and safety of rosuvastatin versus atorvastatin, simvastatin, and pravastatin across doses (STELLAR* Trial). Am J Cardiol 92, 152-160.

71. El Kadi SW, Suryawan A, Gazzaneo MC, et al. (2012) Anabolic signaling and protein deposition are enhanced by intermittent compared with continuous feeding in skeletal muscle of neonates. Am J Physiol Endocrinol Metab 302, E674-E686.
72. Fujita S, Glynn EL, Timmerman KL, et al. (2009) Supraphysiological hyperinsulinaemia is necessary to stimulate skeletal muscle protein anabolism in older adults: evidence of a true age-related insulin resistance of muscle protein metabolism. Diabetologia 52, 1889-1898.

73. Murphy RA, Yeung E, Mazurak VC, et al. (2011) Influence of eicosapentaenoic acid supplementation on lean body mass in cancer cachexia. Br J Cancer 105, 1469-1473.

74. Esteghamati A, Khalilzadeh O, Anvari M, et al. (2008) Metabolic syndrome and insulin resistance significantly correlate with body mass index. Arch Med Res 39, 803-808.

75. Vazquez LA, Rodriguez A, Salvador J, et al. (2014) Relationships between obesity, glycemic control, and cardiovascular risk factors: a pooled analysis of cross-sectional data from Spanish patients with type 2 diabetes in the preinsulin stage. BMC Cardiovasc Disord 14, 153. 